\title{
COMPARISON OF MICRODEBRIDER - ASSISTED TURBINOPLASTY VERSUS ENDOSCOPIC PARTIAL TURBINECTOMY IN CASES OF INFERIOR TURBINATE HYPERTROPHY IN ALLERGIC RHINITIS PATIENTS
}

\author{
Muhammad Ahmed Khan, Faiz Ul Hassan Nawaz*, Muhammad Tahir*, Hina Mazhar*, Muhammad Dawood**, Ejaz Rahim*** \\ Combined Military Hospital Mardan/National University of Medical Sciences (NUMS) Pakistan, *Combined Military Hospital Malir/National University of \\ Medical Sciences (NUMS) Pakistan, ${ }^{* *}$ Combined Military Hospital Khuzdar/National University of Medical Sciences (NUMS) Pakistan, \\ ${ }^{* * *}$ Combined Military Hospital Multan/National University of Medical Sciences (NUMS) Pakistan
}

\begin{abstract}
Objective: To compare microdebrider-assisted turbinoplasty versus endoscopic partial turbinectomy in cases of inferior turbinate hypertrophy in allergic rhinitis patients in terms of relief/improvement of nasal obstruction, post operative bleeding, crusting and synechie formation.

Study Design; Quasi experimental study.

Place and Duration of Study: Combined Military Hospital Mardan and Combined Military Hospital Malir, from Jan 2019 to Jan 2020.

Methodology: A total of 90 patients of allergic rhinitis with severe nasal obstruction due to bilateral inferior turbinate hypertrophy fulfilling the inclusion exclusion criteria were selected. Cases were randomly divided into two groups of 45 each. Group A cases underwent microdebrider assisted turbinoplasty and Group B cases underwent partial turbinectomy via endoscpic approach. They were comparedin terms of post op bleeding, relief of nasal obstruction, post op crusting \& synechie/ adhesions. All the data was entered on SPSS-17 and analyzed.

Results: Out of 90 cases, there were 43 (47.8\%) females and 47 (52.2\%) males with age range from 15-65, mean age 37.68 \pm 11.56 Years. There was only 1 case of post op bleeding after microdebrider assisted turbinoplasty requiring nasal packing in contrast to 6 cases of post op bleeding after endoscopic partial turbinectomy. On one month post op visit, there was no case of nasal crusting in turbinoplasty group in contrast to 7 of mild and 1 of moderate crusting \& 3 synechie/adhesions in endoscopic partial turbinectomy group.

Conclusion: Microdebrider-assisted turbinoplasty is associated with less post operative bleeding and synechie formation as compared to endoscopic turbinectomy.
\end{abstract}

Keywords: Allergic rhinitis, Microdebrider-assisted turbinoplasty, Endoscopic partial turbinectomy, Inferior turbinate hypertrophy.

How to Cite This Article: Khan MA, Nawaz FUH, Tahir M, Mazhar H, Dawood M, Rahim E. Comparison of Microdebrider-Assisted Turbinoplasty Versus Endoscopic Partial Turbinectomy in Cases of Inferior Turbinate Hypertrophy in Allergic Rhinitis Patients. Pak Armed Forces Med J 2021; 71 (Suppl-3): S598-602. D Doi: https://doi.org/10.51253/pafmj.v1i1.4121

This is an Open Access article distributed under the terms of the Creative Commons Attribution License (https://creativecommons.org/licenses/by-nc/4.0/), which permits unrestricted use, distribution, and reproduction in any medium, provided the original work is properly cited.

\section{INTRODUCTION}

Allergic rhinitis has been classified into perennial and seasonal types. Perennial allergic rhinitis persists throughout the year in contrast to seasonal variety in which symptoms occur during specific seasons. ${ }^{1}$ However, all the patients do not fit into this classification scheme. Therefore, allergic rhinitis is now also classified according to duration of symptoms (intermittent or persistent) and severity (mild, moderate or severe). ${ }^{2}$ Rhinitis is called intermittent rhinitis when the duration of the episode of inflammation is less than 6 weeks, and is considered persistent when symptoms continue throughout the year. Prevalence of allergic rhinitis has been reported as $24.62 \%$ in Pakistan. ${ }^{3}$ However much higher prevalence has been reported in USA and

Correspondence: Dr Faiz Ul Hassan Nawaz, Classified ENT Specialist, Combined Military Hospital Malir-Pakistan
Europe, as high as $40 \% .{ }^{4}$ Symptoms are classified as mild when patients are generally able to sleep normally and perform normal activities of daily life including work or school. Symptoms are categorized as moderate to severe if they significantly affect sleep and activities of daily routine. Severe allergic rhinitis has been associated with change in quality of life and decreased performance at work. ${ }^{5}$ A thorough history and physical examination constitute the basis of diagnosing allergic rhinitis. Nasal obstruction in allergic rhinitis patients is a source of constant discomfort and worry for the individuals. Nasal obstruction is due to inferior turbinate hypertrophy in majority of such cases and is persistant. ${ }^{6}$ Inferior turbinate is targeted to amplify and enhance space for airway with medical and surgical options. ${ }^{7}$ Alpha agonist including oxymetazoline, xylometazoline etc are prescribed to decongest nasal 
mucosa to relieve nasal obstruction. But they can only be used for a short duration because of rebound congestion and further nasal obstruction after continuous use. ${ }^{8}$ Topical corticosteroids are also used with varying results, some cases show slight improvement and others are even refractory to the medical treatment. Surgical resection offers the only permanent solution. Surgical procedures for inferior turbianates include conventional partial \& total turbinectomy, submucosal resection, submucosal diathermy, endoscopic turbinectomy, microdebrider assisted turbinoplasty, radio frequency assisted turbinoplasty and lasers assisted turbinectomy. ${ }^{9}$

Previously (before advent of endoscopic technology), turbinectomy was performed by otolaryngologists as more of a blind procedure, major part of turbinate inside nasal cavity being invisible to naked eye, with turbinectomy scissors. This caused more mucosal damage and resulted in frequent peroperative and post operative nasal bleeding. In addition, post operatively nasal packing had to be done which not only caused discomfort, headache, restlessness, insomnia, frequent post operative sinusitis but also aggravated any comorbid conditions in high risk patients i.e. hypertensives/heart patients. ${ }^{10}$

We have carried out this study to compare these two procedures of inferior turbinate resection/volume reduction i.e. endoscopic partial turbinectomy versus microdebrider assisted turbinoplasty. The study will help otorhinolaryngologists to opt for the better procedure with less post operative discomfort, and morbidities to the patients.

\section{METHODOLGY}

The quasi experimental study was carried out at Combined Military Hospital (CMH) Mardan and CMH Malir, from January 2019 to January 2020. Total 90 patients of allergic rhinitis with nasal obstruction due to bilateral inferior turbinate hypertrophy fulfilling the inclusion exlusion criteria were selected from outpatient department of hospitals. Epitool software was used to calculate sample size. Using Epittol sample size calculator, estimated population was $0.06 \%, 11$ desired precision was $0.05 \%$, cofidence interval $95 \%$. Calculated sample size was 87, we took 90 cases as sample size for the study and divided them into two groups of 45 each. Sampling technique was non probability convenient sampling. Patients of allergic rhinitis of any gender, older than 15 years of age with severe nasal obstruction due to bilateral inferior turbinate hypertrophy were included in study. Patients with nasal obstruction due to deviated nasal septum, nasal adhesions, synechie, septal perforations were excluded. Similarly patients who had undergone surgery for turbinate hypertrophy previously were also excluded along with patients with bleeding disorders, liver or renal failure.

Informed consent was taken from all the cases. The cases were randomly divided into two groups of 45 each. Group A cases underwent microdebrider assisted turbinoplasty and Group B cases underwent partial turbinectomy via endoscpic approach. In group A patients, $2 \%$ lignocaine with adrenaline was infiltrated at the anterior end of inferior turbinate. A small incision was made with number 15 blade. Microdebrider unit was set at 3000 rouds per minute oscillating mode and used advanced antero-posteriorly in the inferior turbinate, staying submucosally. Bipolar cautery was used to secure/control bleeding preoperatively, if any. In group B cases, local anesthesia was infiltrated with cotton pledgets soaked in $4 \%$ lignocaine and $0.1 \%$ xylometazoline. Partial turbinectomy was done under vision, working with zero degree endoscope and fine turbinectomy scissors. The medial hypertrophied part of inferior turbinate was resected and hemostasis achieved with bipolar diathermy carefully. No nasal packing was done in patients after both procedures. Post operatively all cases were given oral antibiotic Coamoxiclav, oral paracetamol as pain killer, xylometazoline hydrochloride nasal spray and liquid paraffin nasal drops for one week. No nasal splints were placed post operatively in both groups. Total 90 cases were distributed equally in both hospitals i.e out of total 45 cases of group A were done in $\mathrm{CMH}$ Malir and 45 cases of group B were done in CMH Mardan.

Postoperatively, both groups were compared in terms of efficacy and complications. All the cases were checked postoperatively; on operation day evening, 1st post operative day, at fortnight and one month post op. Post operative bleeding was considered to be present if sufficient bleed occurred resulting in nasal packing and was said to be absent; if no nasal packing was required. Patients were kept admitted for 24 hours then discharged. They were advised to report immediately if nasal bleeding occurred.

Efficacy was assessed by relief of nasal obstruction. Relief of nasal obstruction was categorized into marked improvement/relief, moderate improvement/ relief, mild improvement/relief and no improvement/ relief. Patient was asked to categorize the relief in nasal obstruction from grade 0 (no relief), grade 1 (mild 
relief), grade 2 (moderate relief) and grade 3 (marked relief) in nasal obstruction. Efficacy of procedures was checked on 02 weeks post op visit and one month post op visit. Crusting was categorized into mild, moderate and severe depending on post operative nasal crusts cleared from nose during cleansing by patient. Patient was asked to grade the amount of crusting from none (grade 0), mild (grade 1), moderate (grade 2) and marked (grade 3). Crusting was also assessed on 02 weeks post op visit and one month post op visit. Nasal adhesions/synechie are bands of scars and tissues between nasal septum and lateral nasal wall, formed after nasal surgeries. ${ }^{12}$ Postoperative nasal examination via anterior rhinoscopy was done to assess/see the cases with synechie/adhesions on one month post op visit because it takes $>2$ weeks for formation of adhesions.

Ethical committee permission was taken for subject study (ERB no. 05-2/19). All the data including, age, gender, efficacy, post operative complications i.e. pain, bleeding, crusting and synechie/adhesions were analyzed with help of Statistical Package for Social Sciences (SPSS) 17. Chi sqaure was used to analyze qualitative variables and independent $t$-test was used for quantitative variables. A $p$-value less than 0.05 was taken as significant.

\section{RESULTS}

A total of 90 cases of allergic rhinitis with inferior turbinate hypertrophy, refractory to medical treatment were operated. There were $43(47.8 \%)$ females and 47 (52.2\%) males with age range from 15-65 years. Mean age was $37.68 \pm 11.56$ years. The cases were randomly divided into two groups of 45 each. Group A cases underwent turbinoplasty with microdebrider and group B cases underwent endoscopic partial turbinectomy. Both the groups were comparable in terms of age and gender as shown in Table-I.

Table-I: Age and gender distribution of group A \& B.

\begin{tabular}{l|c|c|c|c}
\hline & Group A & Group B & Total & $\begin{array}{c}p \text { - } \\
\text { value }\end{array}$ \\
\cline { 1 - 4 } Gender & $24(53.3 \%)$ & $23(51.1 \%)$ & $47(52.2 \%)$ & \\
\cline { 1 - 4 } Male & $21(46.7 \%)$ & $22(48.9 \%)$ & $43(47.8 \%)$ & 1.000 \\
\cline { 1 - 4 } Female & $45(50 \%)$ & $45(50 \%)$ & 90 & \\
\cline { 1 - 3 } Total & Age & $38.80 \pm 9.79$ & $37.68 \pm 11.56$ & 0.360 \\
\hline \multicolumn{7}{|l|}{ Mean \pm SD } & $35.56 \pm 13.11$ & 38.80
\end{tabular}

Both the groups were compared in terms of post operative bleeding, post operative crusting \& improvement/relief of nasal obstruction at two weeks and one month duration. There was only $1(2.2 \%)$ case of post op bleeding after microdebrider assisted turbinoplasty requiring nasal packing. In contrast there were 6
$(13.3 \%)$ cases of post op bleeding after endoscopic partial turbinectomy requiring nasal packing. There were only $09(20 \%)$ cases of mild nasal crusting after turbinoplasty on 02 weeks post op visit in contrast to 15 $(33.3 \%)$ cases of mild crusting, $18(40 \%)$ of moderate and $11(24.4 \%)$ of marked crusting on 2 weeks post op visit. There were $02(4.4 \%)$ cases of moderate improvement in nasal obstruction, $43(95.6 \%)$ of marked improvement after turbinoplasty. There were $3(6.7 \%)$ cases of mild improvement, 8 (17.8\%) of moderate improvement and $34(75.6 \%)$ of marked improvement/ relief in nasal obstruction.

On one month post op visit, there was no case of nasal crusting in Turbinoplasty group in contrast to $7(15.6 \%)$ of mild and $1(2.2 \%)$ of moderate crusting in endoscopic partial turbinectomy group. Similarly, 44 (97.8\%) patients said they had marked improvement and $1(2.2 \%)$ had moderate improvement/relief of nasal obstruction after turbinoplasty as compared to 4 $(8.9 \%)$ of mild improvement, $3(6.7 \%)$ of moderate and $38(84.4 \%)$ of marked improvement after endoscopic turbinectomy as shown in Table-II.

Post operative synechie formation which is a known complication of nasal surgery was also compared in these two procedures. There were $3(6.7 \%)$ cases of post op synechie after endoscopic partial turbinectomy, however there were none after turbinoplasty.

\section{DISCUSSION}

Inferior turbinates are important anatomical structures, playing significant role in nasal functions of warming, filtering and humidification of inhaled air. ${ }^{13}$ Inferior turbinate hypertrophy causes persistant nasal obstruction which is quite discomforting and worrisome for patients. Chronic nasal obstruction affects quality of life. ${ }^{14}$ Conventional turbinectomy also had significantly more chances of post operative crusting and synechie/adhesion formation because of inadvertent mucosal damage. Newer procedures including endoscopic partial turbinectomy and microdebrider assisted turbinoplasty are gaining popularity because of less mucosal damage and under vision resection. These benefits of minimum mucosal damage and under vision resection offers safety to surrounding tissues in nose and less post operative bleeding and crusting. 15,16

Surgical reduction in size of turbinates via endoscpic approach and microdebrider are modern turbinate resection techniques. Older conventional methods caused extensive mucosal loss and damage to surrounding tissues. Endoscpoic turbinectomy provides under 
Table-II: Turbinectomy and endoscopic turbinectomy.

\begin{tabular}{|c|c|c|c|c|c|}
\hline Outcome & & $\begin{array}{c}\text { Group A } \\
\text { (Turbinoplasty) } \\
\end{array}$ & $\begin{array}{c}\text { Group B (Endoscopic } \\
\text { Turbinectomy) }\end{array}$ & Total & $\begin{array}{c}p- \\
\text { value }\end{array}$ \\
\hline \multirow{3}{*}{$\begin{array}{l}\text { Post Operative } \\
\text { Bleeding }\end{array}$} & Bleed & $1(2.2 \%)$ & $6(13.3 \%)$ & $7(15.6 \%)$ & \multirow{3}{*}{0.110} \\
\hline & No Bleed & $44(97.8 \%)$ & $39(86.7 \%)$ & $83(184.4 \%)$ & \\
\hline & Total & $45(50 \%)$ & $45(50 \%)$ & 90 & \\
\hline \multirow{5}{*}{$\begin{array}{l}\text { Crusting after } 2 \\
\text { weeks }\end{array}$} & No crusting & $36(80.0 \%)$ & $1(2.2 \%)$ & $37(41.1 \%)$ & \multirow{5}{*}{$<0.01$} \\
\hline & Mild crusting & $9(20.0 \%)$ & $15(33.3 \%)$ & $24(26.7 \%)$ & \\
\hline & Moderate crusting & - & $18(40.00 \%)$ & $18(20 \%)$ & \\
\hline & Marked (Severe) crusting & - & $11(24.4 \%)$ & $11(12.2 \%)$ & \\
\hline & Total & $45(50 \%)$ & $45(50 \%)$ & $90(100 \%)$ & \\
\hline \multirow{4}{*}{$\begin{array}{l}\text { Efficacy/ } \\
\text { Improvement after } \\
2 \text { weeks }\end{array}$} & Mild improvement/relief & - & $3(100 \%)$ & $3(3.3 \%)$ & \multirow{4}{*}{0.022} \\
\hline & Moderate improvement/relief & $2(4.4 \%)$ & $8(17.8 \%)$ & $10(11.122 .2 \%)$ & \\
\hline & Marked improvement/relief & $43(95.6 \%)$ & $34(75.6 \%)$ & $77(171.1 \%)$ & \\
\hline & Total & $45(50 \%)$ & $45(50 \%)$ & $90(100 \%)$ & \\
\hline \multirow{5}{*}{$\begin{array}{l}\text { Crusting after one } \\
\text { month }\end{array}$} & No crusting & $45(100.0 \%)$ & $37(82.2 \%)$ & $82(91.1 \%)$ & \multirow{5}{*}{0.012} \\
\hline & Mild crusting & - & $7(15.6 \%)$ & $7(7.8 \%)$ & \\
\hline & Moderate crusting & - & $1(2.2 \%)$ & $1(1.1 \%)$ & \\
\hline & Marked/ severe crusting & - & - & - & \\
\hline & Total & $45(50 \%)$ & $45(100 \%)$ & 90 & \\
\hline \multirow{4}{*}{$\begin{array}{l}\text { Efficacy/ } \\
\text { Improvement after } \\
\text { one month }\end{array}$} & Mild improvement/relief & - & $4(8.9 \%)$ & $4(4.4 \%)$ & \multirow{4}{*}{0.066} \\
\hline & Moderate improvement/relief & $1(2.2 \%)$ & $3(6.7 \%)$ & $4(4.4 \%)$ & \\
\hline & Moderate improvement/relief & $44(97.8 \%)$ & $38(84.4 \%)$ & $82(91.1 \%)$ & \\
\hline & Total & $45(50 \%)$ & $45(50 \%)$ & 90 & \\
\hline \multirow{3}{*}{ Synechie } & Yes & - & $3(6.7 \%)$ & $3(3.3 \%)$ & \multirow{3}{*}{0.242} \\
\hline & No & $45(51.7 \%)$ & $42(93.3 \%)$ & $87(96.7 \%)$ & \\
\hline & Total & $45(50 \%)$ & $45(50 \%)$ & 90 & \\
\hline
\end{tabular}

vision controlled surgical resection of hypertrophied turbinate tissue. Microdebrider offers resection of itraturbinate hypertrophied tissue with a minimal scar at proximal end of turbinate with preservation of mucosa, thus reducing side-effects associated with mucosal damage. ${ }^{13}$ In our study, we found turbinoplasty technique better in terms of post operative complications i.e. crusting, bleeding, synechie formation but both procedures equally effective in relieving nasal obstruction.

Joniau et al compared powered turbinoplasty with submucosal diathermy of inferior turbinates. They found powered turbinoplasty significantly better than submucosal diathermy in terms of better long term results i.e improvement in nasal obstruction and less post operative crusting. ${ }^{17}$ Kassab et al, compared turbinoplasty with microdebriderverus diode laser and declared both techiques equally safe, reliable and successful with minimal post-operative complications. ${ }^{11}$

Thimmaiah et al, had compared turbinectomy with turbinoplasty and turbinectomy in inferior turbinate hypertrophy, they showed less post operative complications after turbinoplasty i.e. bleeeding, crusting, synechie and headache but in contrast they showed better long term relief of nasal obstrction after total turbinectomy as compared to turbinoplasty ${ }^{18}$, Bozan et al, compared turbinoplasty with outfracture and bipolar cautery and found turbinoplasty more effective in reducing inferior tubinate volume. ${ }^{19}$ Turbinoplasty has excellentbenefit of preserving turbinate mucosa thus greatly reducing post operative granulation formation on damaged/nude mucosa and tissues which is basis of post operative crusting and synechie/ adhesion formation. Turbinoplasty also offers economy of time because of rapid removal of submucosal tissues/bone etc as compared to endoscopic partial turbinectomy which is comparatively time consuming. 18,19

\section{CONCLUSION}

Turbinoplasty technique was found to be better than endoscpic partial turbinectomy in terms of post operative complications i.e., crusting, bleeding, synechie formation but both procedures equally effective in relieving nasal obstruction.

\section{Conflict of Interest: None.}

\section{Authors' Contribution}

MAK: Direct Contribution, FHN: Data Collection, MT: Data Collection, HM: Interpretation, MD: Data analysis, ER: Proof reading.

\section{REFERENCES}

1. Small P, Keith PK, Kim H. Allergic rhinitis. Allergy Asthma ClinImmunol 2018; 14(Suppl-2): 51-55. 


\section{Microdebrider-Assisted Turbinoplasty Vs Endoscopic Partial Turbinectomy}

2. Small P, Frenkiel S, Becker A, Boisvert P, Bouchard J, Carr S, et al. Rhinitis: A practical approach and comprehensive approach to assessment and therapy. J Otolaryngol 2007; 36(suppl-1): s5s27.

3. Khan MA, Usman HB, Akram S, Khan M. Efficacy of lipid based ointment as adjuvant therapy for allergic rhinitis 2017: 67(2): 2528.

4. Khan MA, Akram S, Usman HB, Khan M, Khan AA. Audit of various otorhinolaryngological (Ent) diseases in Shangla valley. Pak armed Forces Med J 2018; 68(3): 531-34.

5. Dykewicz MS, Hamilos DL. Rhinitis and sinusitis. J Allergy ClinImmunol; 2010; 125(Suppl-2): 103-115.

6. Cingi C, Gevaert P, Mosges R, Hox V, Rudenko M, Muluk NB et al. Multi-morbidities of allergic rhinitis: european academy of allergy and clinical immunology task force report. Clin Transl allergy 2017; 7(1): 17-20.

7. Chhabra N, Houser SM. Surgery for allergic rhinitis. Int For Allergy Rhinol 2014; 4(Suppl-2): 79-83.

8. Dokuyucu R, Gokce H, Sahan M, Sefil F, Tas ZA, Tutuk O, et al. Systemic side effects of locally used oxymetazoline. Inj J Clin Exp Med 2015: 8(2): 2674-2678.

9. Cingi C, Ure B, Ozudogru E. Microdebrider-assisted versus radiofrequency-assisted inferior turbinoplasty: a prospective study with objective and subjective measures. Acta Otorhinolaryngol Ital 2010; 30(3): 138-143.

10. Lubianca-Neto JF, Santanna GD, Mauri M, Arrarte JL, Brinckmann CA. Evaluation of time of nasal packing after nasal surgery: a randomized trial. Otolaryngol Head Neck Surg 2000; 122(6): 899-901.
11. Kassab AN, Rifaat M, Madian Y. Comparative study of management of inferior turbinate hypertrophy using turbinoplasty assisted by microdebrider or $980 \mathrm{~nm}$ diode laser. J Laryngol Otol 2012; 126(12): 1231-1237.

12. Khan MA, Jawaid A, Shah HBU, Akram S. Efficacy, post-operative pain and complications of quilting sutures versus intranasal pressure splints in cases of septoplasty without nasal packing: A randomized controlled trial. Isra Med J 2017; 9(6): 395-398.

13. Michael P, Farid M, Kwok M, O'Leary S. Routine nasal packing versus no nasal packing following functional endoscopic sinus surgery. Cochrane Database Sys Rev 2016; 9(1): CD011587.

14. Orlandi RR. Is nasal packing necessary following endoscopic sinus surgery. The Laryngoscope 2004; 114(9): 1541-1544.

15. Jourdy D. Inferior turbinate reduction. Oper Tech Otolayngol Head Neck Surg 2014; 25(3): 160-70.

16. Scheithauer MO. Surgery of the turbinates and the emplty nose syndrome. GMS Curr Top Otorhinolaryngol Head Neck Surg 2010; 9(2): 1-5.

17. Joniau S, Wong I, Rajapaksa S, Carney SA, Wormald PJ. Longterm comparison between submucosal cauterization and powered reduction of the inferior turbinates. Laryngoscope 2006; 119(9): 1612-1619.

18. Thimmaiah VB, Stanley J, Viswanatha B. Turbinectomy versus turbinoplasty: An outcome analysis. Orissa J Otolaryngol Head Neck Surg 2018; 12(1): 29-32.

19. Bozan A, Eris HN, Dizdar D, Gode S, Tasdelen B, Alpay HC. Effect of turbinoplasty versus outfracture and bipolar cautery on the compensatory inferiorturbinatehyperrophy in septoplasty patients. Braj J Otorhinolaryngol 2019; 85(5): 565-570. 